\title{
Influence of Prosthetic Screw Material on Joint Stability in Passive and Non-Passive Implant-Supported Dentures
}

\author{
Aloísio Oro Spazzin ${ }^{1, *}$, Guilherme Elias Pessanha Henriques ${ }^{1}$, Mauro Antônio de Arruda Nóbilo ${ }^{1}$, \\ Rafael Leonardo Xediek Consani ${ }^{1}$, Lourenço Correr-Sobrinho ${ }^{2}$ and Marcelo Ferraz Mesquita ${ }^{1}$
}

\author{
${ }^{1}$ Department of Prosthodontics and Periodontics, Dental School of Piracicaba, State University of Campinas, 901 Ave- \\ nue Limeira, Piracicaba, SP 13414-903, Brazil \\ ${ }^{2}$ Department of Restorative Dentistry, Dental Materials Division, Dental School of Piracicaba, State University of \\ Campinas, 901 Avenue Limeira, Piracicaba, SP 13414-903, Brazil
}

\begin{abstract}
Objectives: This study evaluated the influence of prosthetic screw material on joint stability in implantsupported dentures at two levels of fit. Methods: Ten mandibular implant-supported dentures were fabricated. Twenty cast models were fabricated using these dentures. Four groups $(n=10)$ were tested, according to the vertical fit of the dentures [passive and non-passive] and prosthetic screw materials [titanium (Ti) or gold (Au) alloy]. The one-screw test was performed to quantify the vertical misfits using an optic microscope. The loosening torque for the prosthetic screws was measured 24 hours after the tightening torque $(10 \mathrm{Ncm})$ using a digital torque meter. Data were analyzed by two-way ANOVA and Tukey's test $(\propto=0.05)$. Results: Overall, dentures with passive fit and Ti screws resulted in significantly higher loosening torque of the prosthetic screws $(\mathrm{p}<0.05)$. No significant interaction was found between fit level and screw material $(\mathrm{p}=0.199)$. The prosthetic screw material and fit of implant-supported dentures have an influence on screw joint stability. Ti screws presented higher joint stability than Au screws and minimum of misfit should be found clinically to improve the mechanical behavior of the screw joint.
\end{abstract}

Keywords: Prosthetic screw, fit, vertical misfit, implant-supported dentures, implant prosthesis, loosening torque, screw joint stability.

\section{INTRODUCTION}

Potential distortion can be created at any step of the fabrication process of implant-supported dentures. Several different post-casting techniques have been developed to correct inaccuracies of fit resulting from the fabrication process [1]. However, misfits are a clinical reality, since these procedures are not able to eliminate them completely. Some authors have attempted to define an acceptable level of fit, suggesting values between 10 and $150 \mu \mathrm{m}$ as being clinically acceptable $[2,3]$. Although the preceding values have been reported and used as reference, they are of empirical origin.

Lack of passivity of implant-supported dentures may cause biologic complications of the surrounding tissues, or mechanical failures of the dentures and implant systems [4]. Mechanical complications may include loosening of the prosthetic and abutment screws or fracture of various components in the system [5-7]. Clinical studies frequently report the instability or loosening of prosthetic screws as complications in dental implant therapy [3, 6, 8-10]. Professionals or patients do not perceive the loosening of one screw in dentures, which implicates overload on another screw that

*Address correspondence to this author at the Department of Prosthodontics and Periodontics, Dental School of Piracicaba, State University of Campinas - UNICAMP, 901 Avenue Limeira, Piracicaba, SP 13414-903, Brazil; Tel: 1996332575 or 1921065297 ; Fax: 1921065211 ;

E-mail: aospazzin@yahoo.com.br can also loosen. These ongoing sequences may favor the occurrence of failures, resulting in component fractures or loss of bone tissue surrounding the implants that still have tightened screws by overload of stress on the screw joints and bone-implant interface.

The literature suggests that in addition to the lack of passivity of the dentures [11], several factors can contribute to screw instability, including the screw material [12]. Guda et al. (2008) [13] suggested that materials with higher elastic modulus should be used to manufacture the abutment screws to achieve higher preload. However, the screw joint between implant and machined abutment is in passive state after the torque applied to the screw. When a screw is submitted to a certain torque on the screw joints in a passive state, the only forces created are the clamping forces and preload [14]. In engineering, the aim of a screw or group of screws in almost all joints is to create a clamping force between two or more objects, which are called joint members. The clamping force is the compressive force that two joint members exert on each other, created by the force that the screws are exerting on them. The clamping force on the joint is initially created when joint is assembled and the screws are tightened. This action also creates tension in the screws; this tension is usually called preload at this stage [14].

Implant-supported dentures do not present a perfect fit. Therefore, residual static stresses are created in relation to the misfit size $[15,16]$, suggesting that these residual static stresses could provide differences in screw joint behavior 
Table 1. Prosthetic Screws Used in the Study

\begin{tabular}{|c|c|c|}
\hline Prosthetic Screw & Manufacturer & Alloy Composition* \\
\hline \hline Gold alloy & Conexão Prostheses Systems & $68.5 \% \mathrm{Au}, 8.5 \% \mathrm{Ag}, \mathrm{Cu} \% 23, \leq 0.0014 \% \mathrm{~Pb}, \mathrm{Zn}, \mathrm{Ni}, \mathrm{Cd}, \mathrm{Co}$, \\
& & and Pd \\
\hline Titanium alloy & Conexão Prostheses Systems & $90 \% \mathrm{Ti}, 6 \% \mathrm{Al}$, and $4 \% \mathrm{~V}$ \\
\hline
\end{tabular}

* Alloy composition percentages obtained from the manufacturers.

between a single crown or machined abutment and implantsupported denture. In implant-supported dentures, the effect of the prosthetic screw material on the joint stability is not known.

The aim of this in vitro study was to evaluate the loosening torque of prosthetic screws made of two different materials ( $\mathrm{Ti}$ and $\mathrm{Au}$ alloy) at two levels of fit (passive and nonpassive) in mandibular implant-supported dentures. The hypotheses tested were that: 1) Ti screws present higher loosening torque than Au screws in implant-supported dentures; 2) the loosening torque of prosthetic screws decreases in dentures with non-passive fit.

\section{MATERIALS AND METHODS}

\section{Experimental Design}

Ten mandibular implant-supported dentures were fabricated. Twenty cast models (10 with passive fit and 10 with non-passive fit) were then fabricated using the prosthetic structures. The loosening torque of the prosthetic screws made of different materials, (Table 1) used to retain the dentures, was tested at two levels of fit (passive and nonpassive). Screws were assigned to 4 groups:

- Ti-PF - screws of titanium alloy in dentures with passive fit;

- Ti-NP - screws of titanium alloy in dentures with non-passive fit;

- Au-PF - screws of gold alloy in dentures with passive fit;

- Au-NP - screws of gold alloy in dentures with nonpassive fit.

\section{Prosthetic Structure Fabrication}

A metal matrix was fabricated and five conical abutment analogs with platform diameter of $4.1 \mathrm{~mm}$ (Micro-unit; Conexão Prostheses Systems, São Paulo, SP, Brazil) were fixed to it using transversal screws. The disposition of the abutment analogs (A, B, C, D and E) used in this study simulates a common case of five implants placed between mental foramens, arranged in an arc mode, with 10-mm inter-implant spaces (Fig. 1). A master cast was then fabricated using a splinted impression technique to allow the waxing of ten prosthetic frameworks with calcinable cylinders (Conexão Prostheses Systems) and bar wax cylinders (Wax wire 4.0; Dentaurum, Pforzheim, Germany). The free ends were standardized at a $10-\mathrm{mm}$ distal extension. The frameworks were then cast in cobalt-chrome alloy (Dentaurum) using the lostwax casting technique. Heat-polymerized acrylic resin (Clássico, São Paulo, SP, Brazil) and artificial teeth made of acrylic resin (Vipi Plus; VIPI, Pirassununga, SP, Brazil) were used as veneering material. The size and volume of the dentures were controlled using a silicone matrix (Zeta Labor; Zhermack, São Paulo, SP, Brazil).

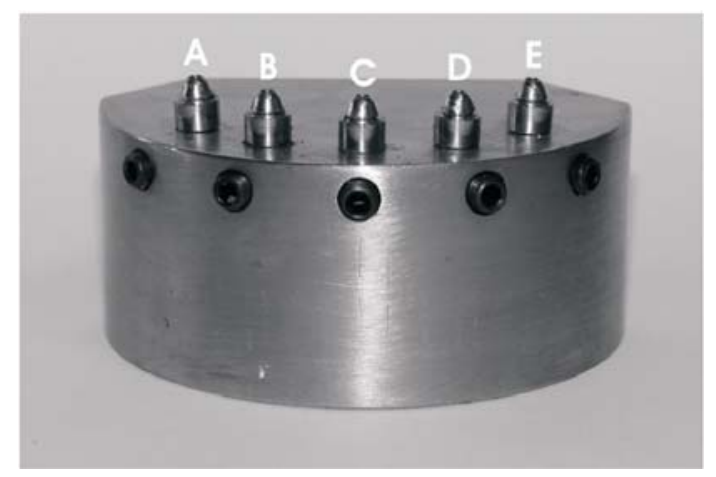

Fig. (1). Metal matrix and disposition of the abutment analogs.

\section{Fit Condition Simulation}

Twenty cast models (10 for passive fit and 10 for nonpassive fit) were fabricated using the prosthetic structures maintaining the positions of the abutment analogs to simulate the two fit levels tested. Assembly of the components as regards the fit levels is shown in Fig. (2). For the passive fit, no rings were used between the abutment analogs (Conexão Prostheses Systems) and framework cylinders of the dentures. For the non-passive fit, three rings of different thicknesses $(100,200$ and $300 \mu \mathrm{m}$, one for each abutment analog, respectively) were used between three of the framework cyl-
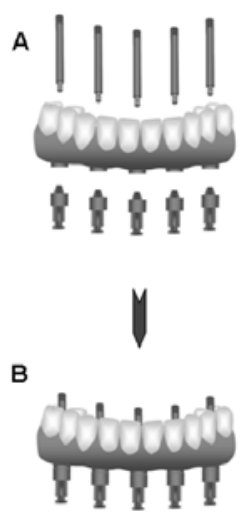
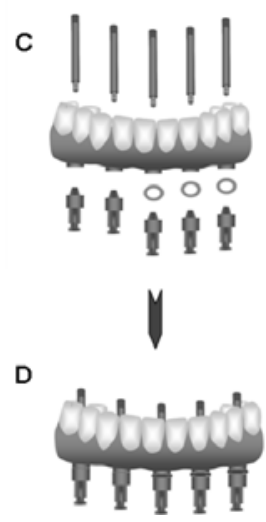

Fig. (2). Schematic illustrations of assembling the components to simulate the different levels of fit: (A) components in passive fit; (B) components assembled in passive fit; (C) components in nonpassive fit; (D) components assembled in non-passive fit with rings ( $\pm 100,200$ and $300 \mu \mathrm{m}$ thickness) inserted between cylinders and abutment analogs. 
A

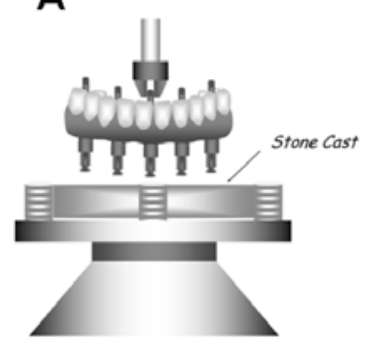

B

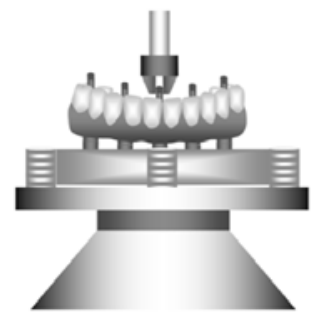

C

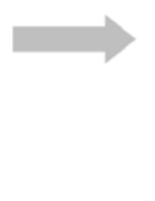

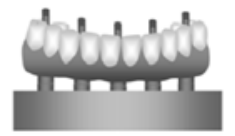

Fig. (3). Schematic illustrations of the cast model fabrication: (A) set assembled; (B) abutment analogs were invested in stone cast; (C) cast models removed from the delineator.

A

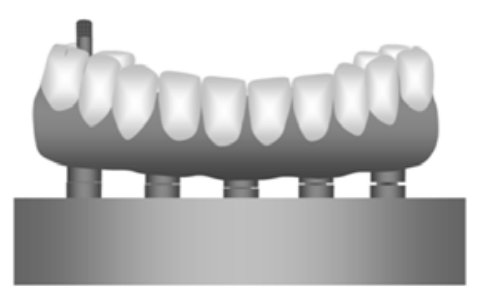

B

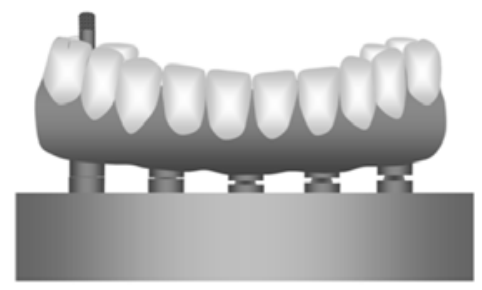

Fig. (4). Schematic illustrations of the two fit conditions submitted to the one-screw test: (A) passive fit; (B) non-passive fit.

inders of the dentures and the abutment analogs $(C, D$ and E); the other abutment analogs (A and B) were screwed directly to the framework cylinders. All these sets were invested in stone cast (type VI Herostone; Vigodent, Rio de Janeiro, RJ, Brazil) using a delineator to standardize the investment procedure (Fig. 3). The rings were added to create a vertical misfit of approximately $250 \mu \mathrm{m}$ in the one-screw test adapted from Tan et al. (1993) [17]; this test was then used to quantify the two fit levels tested (Fig. 4).

\section{Fit Evaluation (One-Screw Test)}

An optic microscope (VMM-150; Walter Uhl, Asslar, Germany) was used to measure the vertical misfit at $120 \mathrm{x}$ magnification. The technique used to measure the misfit was based on the one-screw test protocol of Tan et al. (1993) [17]. This technique involved one Ti screw (Conexão Prostheses Systems) tightened to $10 \mathrm{Ncm}$ onto the abutment "A" using a manual torque meter (Conexão Prostheses Systems). Vertical misfits between platform abutment analogs and the inferior border of the denture framework cylinders were then measured, three times, considering the buccal and lingual faces of the abutments "C" and "E". Next, the Ti screw was loosened and replaced with another screw tightened to 10 Ncm onto abutment " $E$ ", and the vertical misfit of the abutments " $C$ " and "A" was evaluated as previously mentioned.

A total of 24 vertical misfit values were obtained for each prosthetic structure and its cast model, and then the mean of these values was calculated to determine the misfit of the prosthesis. The mean values and standard deviations (SD) with regard to vertical misfit were: 51 (23) $\mu \mathrm{m}$ for passive fit; and 264 (78) $\mu \mathrm{m}$ for non-passive fit.

\section{Loosening Torque Evaluation}

Digital torque meter with a precision of $0.1-\mathrm{Ncm}$ (TQ8800; Lutron, Taipei, Taiwan) was used to tighten the screws and evaluate the loosening torque, involving 100 screws of Ti alloy and 100 screws of Au alloy $(n=10$, screw sets, 5 screws in each set). One researcher only performed the tightening and loosening torque. This researcher was calibrated for several pilot studies, standardizing the speed of the tightening and loosening torque. The cast models were fixed to a laboratory desk using a metal peg, and the prosthetic screws were tightened $(10 \mathrm{Ncm})$ in the sequence $\mathrm{B}, \mathrm{D}$, $\mathrm{C}, \mathrm{A}$ and $\mathrm{E}$ [18]. The loosening torque was evaluated 24 hours after the tightening torque following the same tightening sequence (B, D, C, A and E). The loosening torque of a determined prosthetic screw was evaluated, and this screw was again tightened $(10 \mathrm{Ncm})$ to its abutment, thus the loosening torque of the other prosthetic screws were measured with all the other screws tightened. The mean loosening torque values $(\mathrm{Ncm})$ of the screw sets were submitted to two-way (fit $x$ screw material) analysis of variance (ANOVA) followed by Tukey's test $(\alpha=0.05)$.

\section{RESULTS}

The loosening torque means and standard deviations were: 6.99 (1.03) for Ti-PF, 5.65 (1.18) for Ti-NP, 5.42 (0.99) for Au-PF, and 5.03 (1.33) for Au-NP. The statistical analysis showed significant differences for the fit $(p=0.022)$ and screw material $(\mathrm{p}=0.005)$. Overall, the dentures with passive fit resulted in significantly higher loosening torque of the prosthetic screws compared with non-passive dentures (Table 2); and Ti screws also presented higher loosening 
torque than Au screws (Table 3). The interaction between the two factors was shown to be not significant $(\mathrm{p}=0.199)$.

Table 2. Means (Standard Deviations) of Loosening Torque (Ncm) at Different Levels of Fit

\begin{tabular}{|c|c|}
\hline Fit & Torque Loosening* $^{*}$ \\
\hline \hline Passive fit & $6.20(1.27)^{\mathrm{A}}$ \\
\hline Non-passive fit & $5.34(1.26)^{\mathrm{B}}$ \\
\hline
\end{tabular}

*Distinct capital letters represent significantly different at $\mathrm{p}<0.05$.

Table 3. Means (Standard Deviations) of Loosening Torque (Ncm) for Different Screw Materials

\begin{tabular}{|c|c|}
\hline Screw Material & Torque Loosening* $^{*}$ \\
\hline \hline $\mathrm{Ti}$ & $6.32(1.28)^{\mathrm{A}}$ \\
\hline $\mathrm{Au}$ & $5.22(1.16)^{\mathrm{B}}$ \\
\hline
\end{tabular}

*Distinct capital letters represent significantly different at $\mathrm{p}<0.05$.

\section{DISCUSSION}

Implant-supported dentures present great range in accuracy resulting from the fabrication process. Therefore, the two levels of fit were created to control the misfit values. In 1983, Branemark proposed that this should be at the level of $10 \mu \mathrm{m}$ to enable bone maturation and remodeling in response to occlusal loads [2]. In 1991, Jemt defined passive fit as the level that did not cause any long-term clinical complications and suggested misfits smaller than $150 \mu \mathrm{m}$ were acceptable [3]. The mean vertical misfit value was 51 (23) $\mu \mathrm{m}$ for the dentures placed on the cast models with passive fit, among those referred to as clinically acceptable. While the mean vertical misfit value was 263 (78) $\mu \mathrm{m}$ for the dentures placed on the cast models with non-passive fit, higher than those referred to as clinically acceptable. The overall results of the present study showed that the non-passive dentures reduced the loosening torque of the prosthetic screws, confirming one of the study hypotheses. This decrease in the joint stability may be due the increase of the static stresses present in nonpassive dentures $[15,16]$. Several different post-casting techniques have been developed to correct inaccuracies of fit resulting from the fabrication process [1]. Some studies have shown great reduction in misfit when applying an electroerosion procedure $[1,19,20]$, suggesting a possibility of improving the passivity in implant prosthesis, even after the application of the veneering material.

As regards the screw material, although there may be some plastic deformation in some of the threads when a screw is tightened normally, most of the screws and the joint members respond elastically when the screws are tightened [14]. This can explain the higher loosening torque for $\mathrm{Ti}$ screws compared with Au screws, confirming the other study hypothesis. In other words, the Ti screw probably presented lower plastic deformation than the Au screws, increasing the preload on the screw joint. Guda et al. (2008) [13] evaluated the preload on a screw abutment using finite element analy- sis. The authors suggested that materials with higher elastic modulus should be used for manufacturing abutment screws to achieve higher preload.

An interesting observation can be considered as regards the Ti screws have greater loss of applied torque when used in dentures with non-passive than with passive fit, although no significant interaction between the factors was found. The lower malleability and higher frictional resistance of the $\mathrm{Ti}$ screws could have permitted a smaller contact area between the screw threads and opposing flanges of the abutment than the Au screws, suggesting higher sensitivity of the Ti screw to residual static stresses. Clinically, dynamic stresses are also created, consequently, Ti screws could loosen more easily than Au screws in non-passive dentures. Further investigation is fundamental to evaluate the behavior of the prosthetic screw materials as regards misfits under cyclic loading.

Based in the results of the present study it can be stated that a minimum of misfit must be found clinically to avoid mechanical failures, suggesting that post-casting techniques should used to improve the fit of implant-supported dentures. In addition, Ti screws seem to be a safe and low cost option to obtain high stability of the screw joint. Another limitation of this study concerns the simulated misfits, since only vertical misfits were created, while horizontal and angular misfits are also generated in implant-supported dentures during their fabrication. Horizontal and angular misfits result in generating bending stresses in the implant components [15]. Further studies are necessary to evaluate the effects of these stresses generated by horizontal and angular misfits on joint stability as well as the surrounding bone tissue.

\section{CONCLUSION}

Within the limitations of this in vitro study, it can be stated that titanium screws presented higher joint stability than gold screws in implant-supported dentures. Nevertheless, the maximum possible level of passivity should be found in these dentures to reduce the effect of the static stresses caused by misfits on the stability of the screw joints.

\section{ACKNOWLEDGMENT}

This research was supported by grants 07/55352-8R from FAPESP (The State of São Paulo Research Foundation).

\section{REFERENCES}

[1] Romero GG, Engelmeier R, Powers JM, Canterbury AA. Accuracy of three corrective techniques for implant bar fabrication. J Prosthet Dent 2000; 84: 602-7.

[2] Branemark PI. Osseointegration and its experimental background. J Prosthet Dent 1983; 50: 399-410.

[3] Jemt T. Failures and complications in 391 consecutively inserted fixed prostheses supported by Branemark implants in edentulous jaws: a study of treatment from the time of prosthesis placement to the first annual checkup. Int J Oral Maxillofac Implants 1991; 6: 270-6.

[4] Kan JY, Rungcharassaeng K, Bohsali K, Goodacre CJ, Lang BR. Clinical methods for evaluating implant framework fit. J Prosthet Dent 1999; 81: 7-13.

[5] Zarb GA, Schmitt A. The longitudinal clinical effectiveness of osseointegrated dental implants: the Toronto study. Part III: Problems and complications encountered. J Prosthet Dent 1990; 64: 185-94. 
[6] Naert I, Quirynen M, van Steenberghe D, Darius P. A study of 589 consecutive implants supporting complete fixed prostheses. Part II: Prosthetic aspects. J Prosthet Dent 1992; 68: 949-56.

[7] Gunne J, Jemt T, Linden B. Implant treatment in partially edentulous patients: a report on prostheses after 3 years. Int J Prosthodont 1994; 7: 143-8.

[8] Kallus T, Bessing C. Loose gold screws frequently occur in fullarch fixed prostheses supported by osseointegrated implants after 5 years. Int J Oral Maxillofac Implants 1994; 9: 169-78.

[9] Jemt T, Linden B, Lekholm U. Failures and complications in 127 consecutively placed fixed partial prostheses supported by Branemark implants: from prosthetic treatment to first annual checkup. Int J Oral Maxillofac Implants 1992; 7: 40-4.

[10] Behr M, Lang R, Leibrock A, Rosentritt M, Handel G. Complication rate with prosthodontic reconstructions on ITI and IMZ dental implants. Internationales Team fur Implantologie. Clin Oral Implants Res 1998; 9: 51-8.

[11] McAlarney ME, Stavropoulos DN. Determination of cantilever length-anterior-posterior spread ratio assuming failure criteria to be the compromise of the prosthesis retaining screw-prosthesis joint. Int J Oral Maxillofac Implants 1996; 11: 331-9.

[12] al-Turki LE, Chai J, Lautenschlager EP, Hutten MC. Changes in prosthetic screw stability because of misfit of implant-supported prostheses. Int J Prosthodont 2002; 15: 38-42.

[13] Guda T, Ross TA, Lang LA, Millwater HR. Probabilistic analysis of preload in the abutment screw of a dental implant complex. J Prosthet Dent 2008; 100: 183-93.
[14] Bickford JH. Introduction to the design and behavior of bolted joints: non-gasketed joints. Boca Ration: CRC Press 2007.

[15] Millington ND, Leung T. Inaccurate fit of implant superstructures. Part 1: Stresses generated on the superstructure relative to the size of fit discrepancy. Int J Prosthodont 1995; 8: 511-6.

[16] Uludamar A, Leung T. Inaccurate fit of implant superstructures. Part II: Efficacy of the Preci-disc system for the correction of errors. Int J Prosthodont 1996; 9: 16-20.

[17] Tan KB, Rubenstein JE, Nicholls JI, Yuodelis RA. Threedimensional analysis of the casting accuracy of one-piece, osseointegrated implant-retained prostheses. Int J Prosthodont 1993; 6: 346-63.

[18] Naconecy MM, Teixeira ER, Shinkai RS, Frasca LC, Cervieri A. Evaluation of the accuracy of 3 transfer techniques for implantsupported prostheses with multiple abutments. Int J Oral Maxillofac Implants 2004; 19: 192-8.

[19] Sartori IA, Ribeiro RF, Francischone CE, de Mattos Mda G. In vitro comparative analysis of the fit of gold alloy or commercially pure titanium implant-supported prostheses before and after electroerosion. J Prosthet Dent 2004; 92: 132-8.

[20] Silva TB, De Arruda NMA, Pessanha HGE, Mesquita MF, Guimaraes MB. Influence of laser-welding and electroerosion on passive fit of implant-supported prosthesis. Stomatologija 2008; 10: 96100 .

Received: April 09, 2009

(C) Spazzin et al.; Licensee Bentham Open.

This is an open access article licensed under the terms of the Creative Commons Attribution Non-Commercial License (http://creativecommons.org/licenses/by-nc/3.0/) which permits unrestricted, non-commercial use, distribution and reproduction in any medium, provided the work is properly cited. 